\title{
Mitocondria y muerte celular
}

\author{
Ruth Sánchez ${ }^{1,2,3}$; Gonzalo Arboleda ${ }^{1,4}$ \\ 1. Grupo de Neurociencias, Facultad de Medicina, Universidad Nacional de Colombia. \\ 2. Biotecnología, Universidad Nacional de Colombia. \\ 3. Universidad Colegio Mayor de Cundinamarca, Colombia. \\ 4. Departamento de Patología, Facultad de Medicina, Universidad Nacional de Colombia. \\ Correspondencia: rmsanchezm@unal.edu.co
}

Recibido: 20-08-08 /Aceptado: 25-09-08

\section{Resumen}

Recientemente se ha definido el papel decisivo que tienen las mitocondrias en los mecanismos de muerte celular, los cuales se han explicado en diversos modelos, donde la permeabilización de la membrana externa mitocondrial y la liberación de proteínas importantes del espacio intermembranal de la mitocondria son características importantes que definen este proceso. Específicamente proteínas pro-apoptóticas tales como Citocromo c, Smac/diablo entre otras, son liberadas durante estadios tempranos del proceso apoptótico. Los mecanismos por los cuales estas proteínas son liberadas dependen presumiblemente del tipo celular y la naturaleza del estimulo. La activación de las caspasas (proteasas de cisteína) durante la apoptosis temprana parece estar regulada principalmente por la familia de las proteínas Bcl-2, cuya función principal es el control de la permeabilidad de la membrana mitocondrial a través de la formación o regulación de poros, en particular el poro de permeabilidad transicional mitocondrial. La presente revisión busca mostrar una visión global del papel de la mitocondria en los procesos de muerte celular, en la apoptosis, y en algunos de los mecanismos moleculares involucrados en su regulación.

Palabras clave: apoptosis, caspasas, citocromo c, ciclo de Krebs, glucólisis, mitocondria.

\section{Abstract \\ Mitochondria and cell death}

Recently the decisive role of mitochondria in the mechanisms of cell death has been defined in diverse models, where the permeability of the mitochondrial outer membrane and the important protein release of the intermembrane space of mitochondria are important characteristics that define this process. Specifically pro-apoptosis proteins such as Cytochrome c, Smac/devil among others, are released during early stages of the apoptosis process. The mechanisms by which these proteins are released depend presumably on the cell type and the nature of the stimulus. The activation of caspases (proteases of cysteine) during the early apoptosis seems to mainly be regulated by the family of the Bcl-2 proteins, whose main function is the control of the permeability of the mitochondrial membrane through the formation or regulation of pores, in particular the pore of mitochondrial transitional permeability. This revision intends to show a global vision of the role of mitochondria in the processes of cell death, in apoptosis and in some of the molecular mechanisms involved in its regulation.

Key Words: apoptosis, caspases, cytochrome c, glycolysis, Krebs cycle, mitochondria. 


\section{Introducción}

Hasta hace poco tiempo se consideraba que la principal función de la mitocondria estaba limitada a la producción de energía en forma de ATP. Sin embargo, se ha descrito un nuevo papel para este organelo dentro del proceso de la muerte celular programada (Apoptosis), actuando de reservorio de proteínas apoptóticas como el citocromo $C$, Smac / Diablo, el factor inductor de apoptosis, (AIF), endonucleasa $G$ y las procaspasas 2,3,8 y 9 (1). La liberación de estas proteínas conduce a una secuencia de cambios morfológicos que van desde la condensación nuclear hasta la exposición de la fosfatidilserina y de moléculas de adhesión en la superficie de las células que han entrado en apoptosis (2). Por tanto, parece que la mitocondria actúa como el escenario integrador de una cadena de estímulos inductores para la apoptosis y desencadena una serie de cascadas de señalización que terminan con la muerte de la célula. Los avances en este campo han generado nuevas preguntas a cerca de las funciones y mecanismos regulatorios de este proceso, entre las que se incluyen, ¿cómo controla la familia Bcl-2 la liberación de proteínas de la mitocondria?, ¿qué papel juega el poro de permeabilidad transicional mitocondrial? (del inglés, mitocondrial permeability transition pore $\mathrm{mPTP})$, entre otros.

\section{Mitocondria: aspectos estructurales y fisiológicos}

\section{Generalidades}

La mitocondria se conoce desde hace más de un siglo y en su historia se encuentra el trabajo de cientos de investigadores de distintas disciplinas e intereses. El primero en describir las mitocondrias fue R. Atman en 1884; las identificó como unas estructuras intracelulares a las que llamó mioblastos. Años después, Benda denominó a esas estructuras mitocondrias, del griego mitos que significa hilo y condos granulo. Las mitocondrias son organelos intracelulares presentes en prácticamente todas las células eucariotas. Están encargados de suministrar la mayor parte de la energía necesaria para la actividad celular, sintetizan ATP a expensas de glucosa, ácidos grasos y aminoácidos por medio de la fosforilación oxidativa (3).
La mitocondria tiene un tamaño variable entre $0.1 \mu \mathrm{m}$ y $0.5 \mu \mathrm{m}$ de diámetro y pueden alcanzar una longitud máxima de $7 \mu \mathrm{m}$, sin embargo éste depende de la actividad de la célula (4). En promedio hay unas 2000 mitocondrias por célula, pero las que desarrollan mayor actividad metabólica, como las musculares, tienen un número mayor en comparación con las poco activas, por ejemplo las células epiteliales (5).

\section{Aspectos estructurales}

La mitocondria posee un sistema de doble membrana una externa y una interna, que separan tres espacios bien definidos: el citosol, el espacio intermembranal y la matriz mitocondrial. Las membranas mitocondriales se caracterizan por bajos niveles de ciertos lípidos como el ácido fosfatídico, las esfingomielinas y los glicolípidos característicos de las membranas de las células eucariotas. Presenta un bajo porcentaje de colesterol entre el 7\%$11 \%$ en comparación con la membrana de una célula (25\%-34\%) (4). El alto contenido de fosfatidilcolina, fosfatidilinositol, cardiolipinas y la escasa cantidad de fosfatidilserina, hacen que la membrana mitocondrial sea semejante a las membranas de ciertas bacterias.

Al igual que las membranas plasmáticas, las mitocondriales poseen una simetría en la distribución de los lípidos no sólo entre las membranas interna y externa, sino también entre las capas interna y externa de la bicapa lipídica. De modo que una alteración en esta distribución tiene consecuencias para la función y supervivencia de las mitocondrias y aún de la célula misma en el proceso de la apoptosis $(6,7)$.

La membrana externa es una bicapa lipídica, continua, uniforme y está constituida por $40 \%$ de lípidos y $60 \%$ de proteínas que forman poros, llamados porinas o canales aniónicos dependientes de voltaje (del inglés voltage dependent anion channel: VDAC) que la hacen permeable a iones, metabolitos y muchos polipéptidos (7). Esto asegura el paso, por transporte pasivo, de moléculas citosólicas de peso molecular igual o inferior a 10.000 Da y un diámetro aproximado de $20 \AA$. También posee enzimas que convierten sustratos lipídicos en formas que van a ser subsecuentemente metabolizadas en la matriz, como por ejemplo la esfingomielinasa que se encarga de metabolizar la esfingomielina (4). 
La membrana externa posee receptores de importación capaces de reconocer secuencias de direccionamiento de las proteínas citosólicas destinadas a las mitocondrias, por ejemplo las ADN y ARN polimerasas mitocondriales. También se observan elementos de translocación de proteínas o de complejos de importación sintetizados en el citoplasma. En el momento de la importación de una proteína estos complejos se asocian temporalmente a los complejos de importación de la membrana interna y de esta forma las membranas externa e interna quedan temporalmente unidas (4). Otros complejos favorecen la importación del colesterol, que es necesario para la síntesis de esteroides desarrollados en la mitocondria. Además, la membrana externa posee proteínas que pueden establecer, junto con la actina, uniones dependientes de ATP y proteínas antiapoptóticas de la familia $\mathrm{Bcl}-2$, cuya sobre expresión tiene como consecuencia el bloqueo de la apoptosis (3).

La membrana interna difiere en su organización molecular de la membrana externa. Posee $80 \%$ de proteínas y $20 \%$ de lípidos. Se caracteriza por formar cierto número de repliegues que se denominan crestas y que incrementan el área total de la superficie interna. Estas crestas aparecen como estructuras lamelares o tubulares, cuyo número está relacionado con las demandas energéticas de la célula (4). Esta membrana es impermeable a muchos solutos; todo paso a través de ella se realiza gracias a proteínas transportadoras, que en su mayoría son hidrofóbicas. Tiene un bajo contenido de colesterol y un alto contenido de cardiolipina (difosfatidil glicerol), lo que permite que los lípidos citosólicos entren a la matriz para llevar a cabo la $\beta$-oxidación. Estas características la hacen poco permeable a ciertos iones, excepto al ATP, ADP, ácido pirúvico, oxígeno y agua. Contiene tres tipos de proteínas: 1. Las que llevan a cabo las reacciones de oxidación de la cadena respiratoria, 2. Un complejo enzimático llamado ATPasa, que sintetiza el ATP en la matriz y 3. Proteínas transportadoras específicas que regulan el paso de metabolitos dentro y fuera de la matriz (5).

Entre las dos membranas queda delimitado un espacio intermembranal, compuesto de un líquido similar al hialoplasma, que contiene todas las moléculas que las porinas de la membrana externa dejan pasar (6). Este espacio es rico en protones, los cuales proceden del funcionamiento de los complejos de la cadena respiratoria y desempeñan un papel esencial en la fosforilación de ADP (4). El espacio intermembranal contiene también componentes claves implicados en la muerte celular de tipo apoptótico, como algunas caspasas, el factor inhibidor de la apoptosis (AIF) y el citocromo $c$, que se localiza sobre la cara interna de la membrana interna (8).

En microscopia electrónica la matriz mitocondrial se observa ligeramente densa y finamente granulosa, debido a los gránulos densos e irregulares de $50 \mathrm{~nm}$ de diámetro propios de las acumulaciones de iones de $\mathrm{Ca}^{++} \mathrm{y} \mathrm{Mg}^{++}(7)$. Alberga moléculas de ADN y ARN mitocondrial, contiene iones, metabolitos a oxidar y ribosomas tipo $70 \mathrm{~S}$ similares a los de las bacterias, llamados mitoribosomas, que realizan la síntesis de algunas proteínas mitocondriales (6.9). En la matriz mitocondrial tienen lugar diversas rutas metabólicas, por ejemplo las enzimas responsables de la oxidación del ácido pirúvico en el ciclo de Krebs y en la beta-oxidación de los ácidos grasos (5).

\section{Aspectos funcionales}

Eugene Kennedy y Albert Lehninger descubren en 1948 que la mitocondria en los eucariotas es el lugar donde se realiza la fosforilación oxidativa, lo que marca el inicio de la fase moderna de los estudios sobre las transducciones de energía biológica (5). En las mitocondrias se desarrollan distintas reacciones bioquímicas catabólicas que liberan importantes cantidades de energía, la cual se almacena en forma de ATP y es usada para mantener la actividad celular (6). En los organismos aeróbicos más del 90\% del ATP proviene de las mitocondrias, el resto se forma en la glicólisis anaeróbica. El ATP es una molécula relativamente simple, formada por una ribosa, una adenina y tres fosfatos. La unión entre los fosfatos se conoce como unión pirofosfato. Cuando el ATP se hidroliza a ADP y fosfato, se liberan aproximadamente 7.500 calorías por mol (4).

La fosforilación oxidativa es la culminación del metabolismo productor de energía en los organismos aeróbicos. Todos los pasos oxidativos en la degradación de glúcidos, grasas y aminoácidos convergen en esta etapa de la respiración celular en la que la energía de oxidación impulsa la síntesis de ATP. La oxidación de la glucosa se produce en dos etapas. La primera se conoce como glicólisis y la segunda es la respiración que está compuesta 
de dos partes: el ciclo de Krebs y el transporte terminal de electrones. La glicólisis se produce en el citosol y las dos etapas de la respiración en la mitocondria (5).

La glicólisis es un proceso que tiene como objeto la oxidación de la glucosa para producir ácido pirúvico y formar una pequeña cantidad de ATP a partir de ADP y fosfato. Durante este proceso son transferidos a las coenzimas aceptoras pocos electrones y sus protones acompañantes. El sistema dedicado al transporte de los electrones está compuesto por cuatro complejos enzimáticos fijos y dos transportadores de electrones móviles: el complejo I o NADH deshidrogenasa que contiene flavina mononucleótido (FMN), el complejo II o succinato deshidrogenasa; ambos ceden electrones al coenzima Q o ubiquinona; el complejo III o citocromo $b c_{1}$ cede electrones al citocromo $c$ y el complejo IV o citocromo c oxidasa cede electrones al oxígeno para producir dos moléculas de agua, Figura 1 (4).

Proteínas transportadoras específicas en la membrana interna importan piruvato, ADP y pirofosfato hacia la matriz mitocondrial, y exportan el ATP. El NADH, generado en el citosol, no es transportado directamente a la matriz debido a la impermeabilidad de la membrana. Un sistema de lanzaderas transporta los electrones desde el NADH citosólico hacia el NAD+ de la matriz.

El oxígeno se difunde hacia la matriz y el $\mathrm{CO}_{2}$ lo hace hacia fuera. Los ácidos grasos se unen a la coenzima $\mathrm{A}$ (CoA) en la membrana mitocondrial externa, luego el grupo acilo se separa de la CoA y se liga a la carnitina para ser transportado a través de la membrana interna. El ácido graso se vuelve a unir a un $\mathrm{CoA}$ en el lado matricial de la membrana interna. La oxidación del piruvato en el ciclo del ácido cítrico genera NADH y FADH2. De estas coenzimas reducidas se transfieren los electrones al oxígeno a través de los cuatro complejos transportadores de electrones y al mismo tiempo se transportan iones de hidrógeno desde la matriz al espacio intermembranal, con la cual se genera la fuerza protón motriz. Luego el complejo F0F1 dirige la fuerza protón motriz para sintetizar el ATP (4).

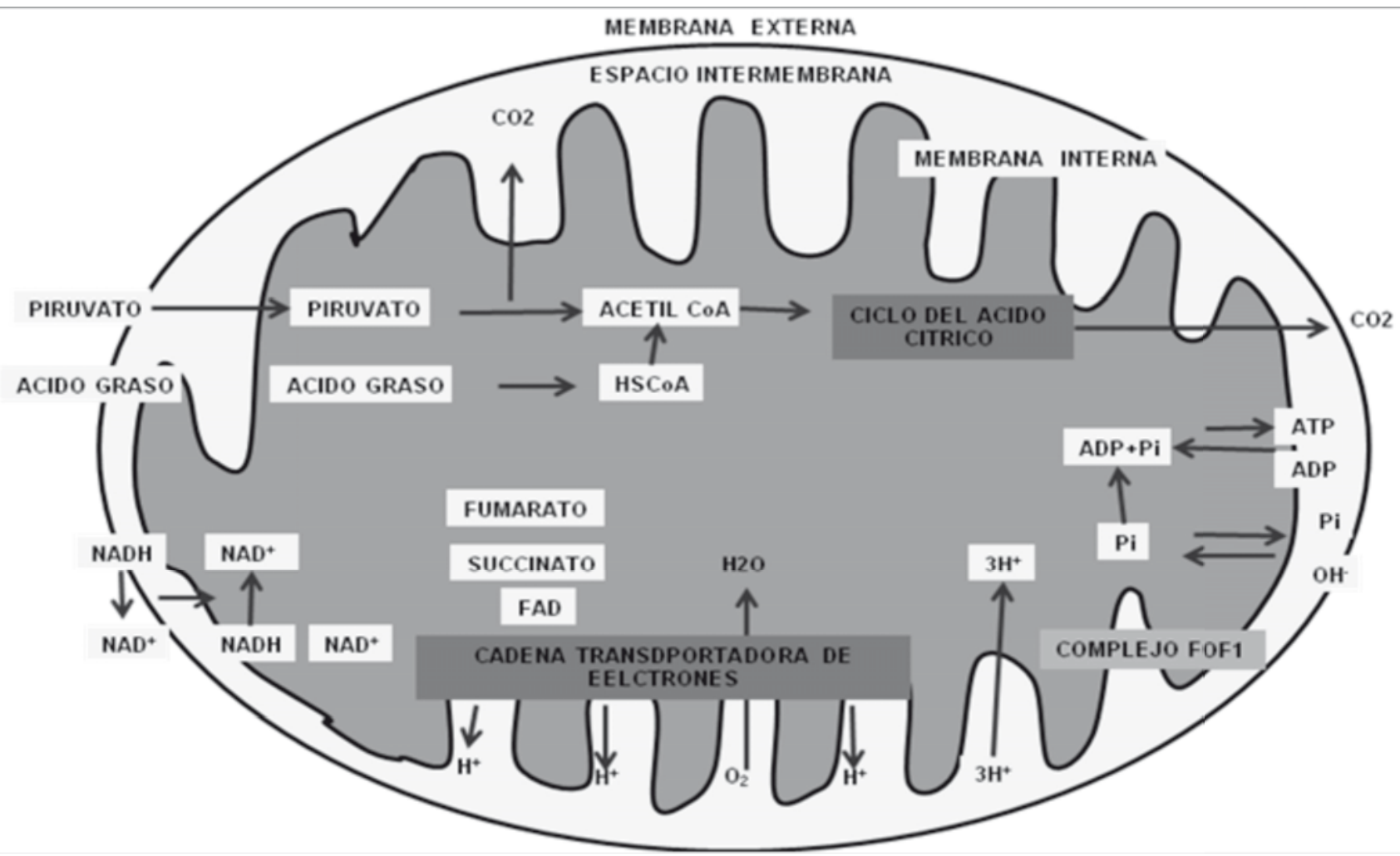

Figura 1. Oxidación aeróbica del piruvato en la mitocondria. 1. Transporte de los metabolitos hacia el interior de la membrana. Piruvato deshidrogenasa, ciclo del ácido cítrico y metabolismo de los ácidos grasos. 2. Transporte de electrones desde el NADH y el FADH2 hacia el oxigeno, generación de fuerza protón motriz. 3 Síntesis de ATP por el Fo-F1 mediante el empleo de la fuerza protón-motriz. Tomada y Modificada de H. Lodish (4). 


\section{El Potencial de membrana mitocondrial.}

La energía que se obtiene a través de la transferencia de electrones a lo largo de la cadena transportadora es usada para bombear protones desde la matriz mitocondrial hacia el espacio intermembranal, creando un gradiente electroquímico de protones a través de la membrana mitocondrial interna $(\Delta \Psi \mathrm{m}$ : potencial de membrana mitocondrial). Este gradiente de protones permite a la ATP sintasa utilizar el flujo de $\mathrm{H}^{+}$generados para producir ATP a partir de adenosina difosfato (ADP) y fosfato inorgánico. De esta manera, la membrana mitocondrial interna separa dos compartimientos de diferente concentración de $\mathrm{H}^{+}$, lo que produce diferencias en la concentración química $(\Delta \mathrm{pH})$ y en la distribución de la carga $(\Delta \Psi \mathrm{m})$ a través de la membrana. El resultado neto es la fuerza protón motriz $(\Delta \mathrm{G})(4)$.

La regulación del potencial de la membrana interna de la mitocondria está dada, en parte, por la vía PI3K/Akt. Se ha demostrado que la activación de Akt, promueve la supervivencia celular neuronal por la activación de factores de crecimiento que actúan contra varios estímulos apoptóticos a través de la modulación de la actividad de la proteína $\mathrm{Bcl}-2$ en las neuronas y de Bcl-xL en células de Schwann, ya que regulan la actividad del poro de permeabilidad transicional de la mitocondria e impiden la liberación de proteínas apoptoticas (10,11). Además, los blancos de señalización de PI3K favorecen la transcripción de genes como CREB y el factor nuclear $\kappa \mathrm{B}(\mathrm{NF}-\kappa \mathrm{B})$, que codifican para proteínas antiapoptóticas (12).

\section{Muerte celular y mitocondria}

Aunque no son claros los mecanismos que controlan la muerte celular, estudios detallados sobre la morfología de las células que mueren durante el desarrollo, han permitido identificar varias formas de muerte celular, entre ellas: autofagía, muerte celular no lisosomal, catástrofes mitóticas, paraptosis, necrosis y apoptosis ó muerte celular programada; de las cuales, las dos últimas han sido las más estudiadas (8). La apoptosis es el mecanismo de muerte celular que se ha relacionado con mayor frecuencia a las enfermedades neurodegenerativas del sistema nervioso central. Por tal razón, se profundizará en sus mecanismos y su relación con las alteraciones mitocondriales.

\section{Apoptosis}

La apoptosis es un mecanismo regulador esencial que interviene en la homeostasis tisular y en el desarrollo normal, eliminando las células innecesarias. El término apoptosis (del griego: caída) fue usado originalmente por los botánicos, pero a principios de la década de 1970, los científicos escoceses Kerr, Wyllie y Currie lo reacuñaron para describir la muerte de células del hígado, que después de encogerse -y marchitarse- se desprendían de este órgano como hojas en el otoño (6).

El nemátodo microscópico Caenorhabditis elegans ha sido utilizado como modelo experimental de apoptosis, ya que durante su desarrollo, 131 de 1090 células embrionarias mueren por este proceso y además se conoce la localización y transformación precisa de todas sus células individuales (13). En este modelo se han identificado algunos genes necesarios para promover o impedir la muerte celular, denominados genes ced (Caenorhabditis elegan death). La presencia del gen ced-9 protege de la muerte celular, mientras que ced-3 y ced-4, la favorecen. En estudios posteriores, diversos investigadores han encontrado homólogos en los mamíferos: la familia de proteínas $\mathrm{Bcl}-2$ y la familia de las caspasas respectivamente $(14,15)$.

\section{Apoptosis vs. necrosis}

La apoptosis y la necrosis se diferencian claramente: los agentes desencadenantes de la necrosis son de carácter tóxico, traumático o hipóxico, siempre patológicos. Además, se observan numerosas células vecinas comprometidas en este proceso. Hay destrucción de la membrana celular lo que permite el escape al exterior de elementos tóxicos que provocan un proceso inflamatorio con efecto nocivo en el organismo. Según la extensión del proceso, el material cromatínico muestra un patrón de dispersión irregular y la desintegración celular no implica gasto de ATP.

En el proceso apoptótico se afectan determinadas células, sin que necesariamente sean contiguas, ni que se vea comprometida toda la población de células que conforman un área tisular. La membrana celular no se destruye, lo que impide el escape de su contenido al espacio extracelular, favoreciendo un proceso "silencioso", sin inflamación. En el citoplasma se produce granulación fina, con conservación de algunos organelos, en especial 
las mitocondrias. A nivel nuclear la cromatina se condensa en varios sectores formando los llamados cuerpos apoptóticos, lo que requiere gasto de ATP. La membrana celular se recoge sobre las elevaciones globuliformes que forman los elementos deteriorados del citoplasma y el núcleo. Finalmente los cuerpos apoptóticos externalizan algunos fosfolípidos de membrana, como la fosfatidil serina y algunas moléculas de adhesión, que los fagocitos reconocen, lo que impide que se produzca una reacción inflamatoria en el resto del tejido (16).

\section{Las caspasas: enzimas fundamentales para la ejecución de la muerte}

La mayoría de estímulos que conducen a la apoptosis convergen en la mitocondria y provocan una permeabilización de su membrana externa. Con la permeabilización se liberan una serie de proteínas que activan las caspasas $(1,2,16)$. Éstas inducen la mayoría de los acontecimientos proteolíticos de la apoptosis y son consideradas como responsables finales de la muerte celular. En el citoplasma y en el espacio intermembranal de las mitocondrias se localizan en forma de procaspasas, las cuales son activadas por clivaje y actúan como ejecutoras que escinden moléculas de supervivencia celular y ponen en marcha las actividades que inducen la muerte de la célula (17).

Actualmente se han identificado 14 caspasas en mamíferos; todas ellas presentan una secuencia conservada de 5 aminoácidos (QACR(N/Q) G) en el sitio activo. Las caspasa 1 y 11 funcionan principalmente en el procesamiento de citocinas, mientras que las caspasas 2,3 , $6,7,8,9,10$ y 12 participan en la regulación y ejecución de la apoptosis $(17,2)$. Las caspasas son divididas en dos grupos: caspasas iniciadoras con un predominio largo $(2,9,10,16)$ y caspasas efectoras con un prodomino corto $(3,6,7)$ que actúan sobre las endonucleasas y son las responsables directas de la fragmentación del ADN $(18,19)$. La cadena de degradación proteica tiene sucesivos clivajes dependientes de la ubicación del ácido aspártico que se repite en la estructura de la enzima. La función de las otras caspasas está por describirse (20). Actualmente hay dos vías alternativas para activar las caspasas. Una es iniciada por señales externas que activan un receptor de muerte en la superficie celular (vía extrínseca). La otra es disparada por cambios en la integridad mitocondrial (vía intrínseca) $(21,22)$.

\section{Vía extrínseca}

Las células de los mamíferos expresan receptores localizados en su membrana plasmática. La unión de ligandos a estos receptores desencadena la activación de las caspasas y una cascada de reacciones que finalizan con la muerte celular. Algunos de estos receptores son el Fas, el receptor-1 del factor de necrosis tumoral (TNF-R1) y el DR3 (23). La fijación del Fas ligando a su receptor (Fas) provoca el reclutamiento citoplasmático del adaptador FADD (del inglés Fas-associated death domain protein), al cual fija la procaspasa 8. Este complejo se realiza por interacciones homofílicas entre secuencias polipeptídicas designadas como dominios efectores de muerte (DED, del ingles death e冈ector domain), que están presentes en ambas proteínas. La asociación Fas/FADD y procaspasa 8 forma un complejo denominado Complejo de señalización de muerte (DISC, por sus iniciales en inglés Death Inducing Signalling Complex). La procaspasa 8 es activada en el DISC por una proteólisis y actúa sobre las procaspasas 3, 6 y 7 que coordinan, entonces, la muerte celular. Algo similar sucede con el receptor TNF-R1 $(22,23)$.

\section{Vía intrínseca: la mitocondria como mediador en el proceso de apoptosis.}

Durante décadas se consideró a la mitocondria como un organelo encargado exclusivamente de oxidar sustratos, produciendo agua en un proceso acoplado a la fosforilación en la producción de ATP. En la actualidad se sabe que en la mitocondria existe un proceso latente de transporte, conocido como "permeabilidad transicional mitocondrial", cuya activación se presenta bajo ciertas condiciones y se traduce en la permeabilización de la membrana mitocondrial a iones que incluyen el calcio (24). Se ha propuesto que esta permeabilidad mitocondrial, podría ser una de las vías de conducción de moléculas pro-apoptóticas.

Hoy en día, se sabe que el poro se abre cuando hay un exceso de calcio y fosfato, lo que despolariza la mitocondria y desacopla la cadena respiratoria. El poro de permeabilidad transicional mitocondrial (PTPm), favorece la cascada de caspasas y favorece la muerte celular al liberar factores inductores de apoptosis como el citocromo $c$, factores de fragmentación del núcleo y proteínas como SMAC/ DIABLO que neutralizan los inhibidores endógenos de 


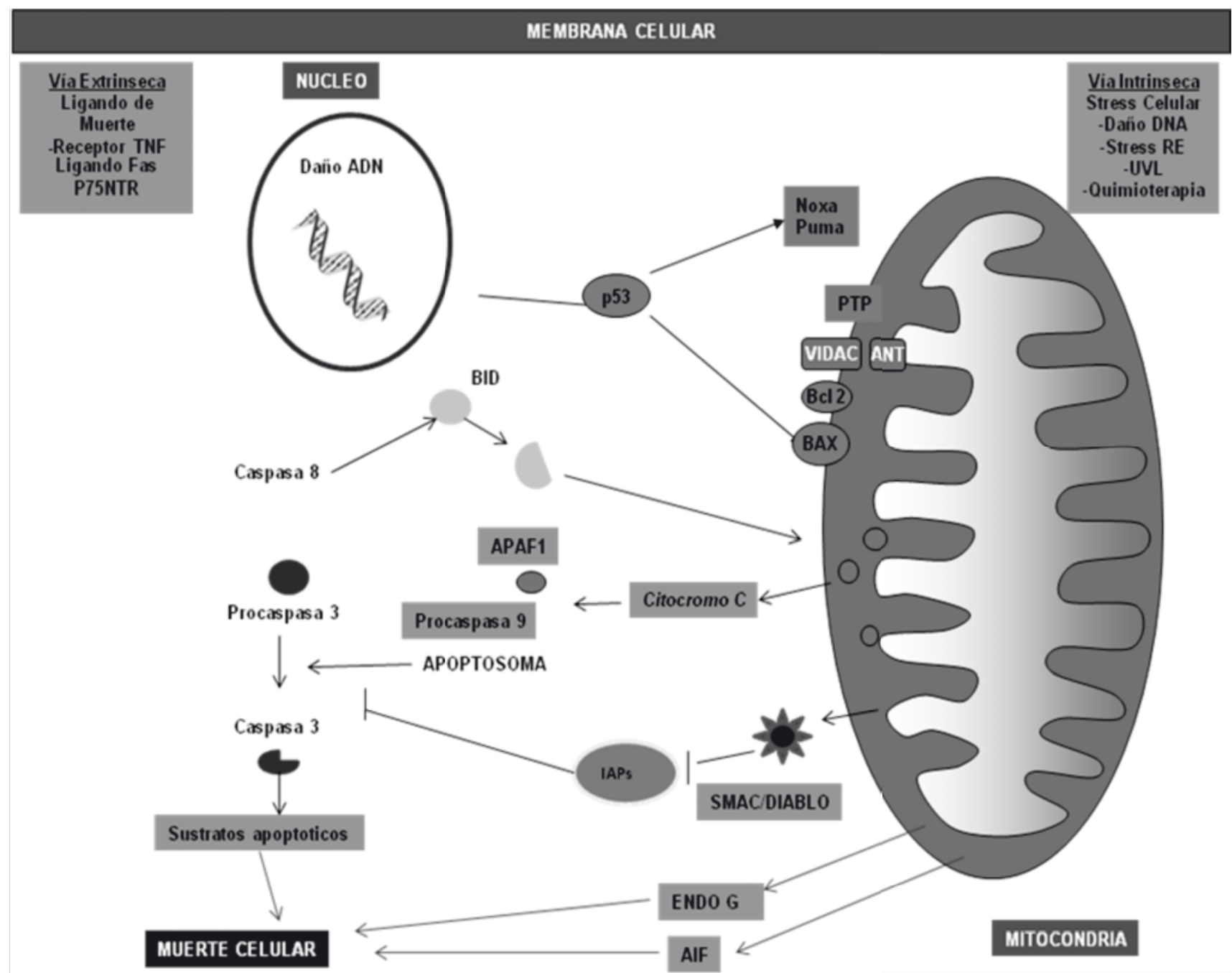

Figura 2. Mitocondria como mediador en el proceso de apoptosis. Estímulos apotóticos activan proteínas efectoras que se translocan desde el citosol a la mitocondria y originan la liberación de proteínas apoptoticas a través de un mecanismo desconocido que involucra miembros de la familia Bcl2 y el poro de permeabilidad transicional que ocasiona la liberación de proteína inhibidoras y activadores de la apoptosis. Factor inductor de la apotosis (AIF), promotor de fragmentación nuclear EndoG, proteína inhibidora de apoptosis (IAP). Tomado y modificado de Parone PA (26).

la apoptosis (AIF, por sus iniciales en inglés Apoptosis Inducing Factor), Figura 2 (25,26).

La proteína de translocación mitocondrial (TSPO) de $18 \mathrm{KDa}$, interactúa con VDAC para desempeñar un papel en la apoptosis. En este contexto, TSPO parece participar en la generación de especies reactivas de oxígeno (ROS). Esta generación de ROS induce la activación de la vía mitocondrial de la apoptosis. ROS son conocidos por ser capaces de liberación de citocromo c. $(27,28)$. Evidencias recientes indican que la caspasa 2 puede estar directamente involucrada en la liberación de citocromo $c$ desde la mitocondria en las células apoptóticas (27). Esta caspasa es la más conservada entre las especies y fue la primera clonada en humanos. Se activa tempranamente en respuesta a stress genotóxico y puede funcionar como modulador del camino apoptótico mitocondrial. Recientes estudios han demostrado que la activación de la caspasa 2 ocurre dentro de un complejo multiproteíco, con proteínas inducidas por el gen supresor tumoral p53, PIDD (del ingels p53-induced protein with death domain), las proteínas adaptadoras de muerte RAIDD y otras proteínas (30).

La permeabilización de la membrana externa y consiguiente liberación de citocromo $c$ es considerada un paso clave y de no retorno en el inicio del proceso apoptótico. Una vez en el citoplasma, el citocromo $c$, junto a la molécula adaptadora Apaf-1 participa en la formación del complejo del apoptosoma, lo que resulta en el reclutamiento y procesamiento de la procaspasa 9 hacia su forma activa (caspasa 9), en presencia de ATP. 


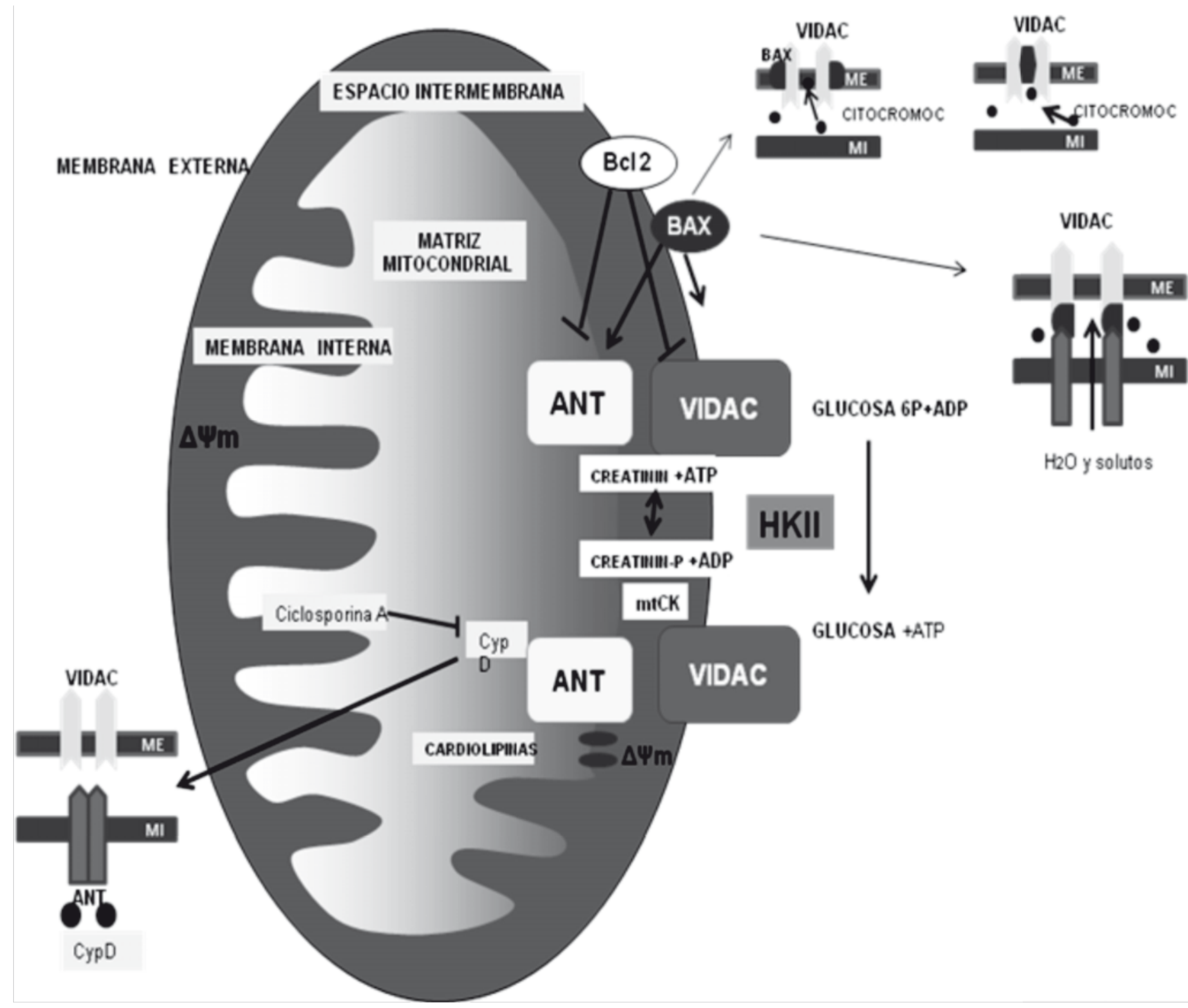

Figura 3. Estructura hipotética del poro de permeabilidad transicional mitocondrial. Canales aniónicos dependientes de voltaje (VDAC), Translocador de nucleotidos de andenina (ANT), Receptor periférico de benzodiacepinas (PBR), creatinina kinasa mitocondrial (mtCK), Ciclofilina D peptidil prolil isomerasa (Cyp D), familia Bcl-2. Tomado y modificado de Zamzani (32).

Subsecuentemente la caspasa 9 cliva y activa la procaspasa 3 y 7 (caspasas efectoras) que son las responsables del clivaje de varias proteínas que llevan a las características bioquímicas y morfológicas de la apoptosis $(31,2)$.

\section{El poro de permeabilidad transicional mitocondrial (PTPm)}

El PTPm se ubica en los sitios de unión entre las membranas interna y externa de la mitocondria. Es un complejo multiproteíco capaz de formar poros no selectivos en la membrana interna. Los componentes estructurales del poro son: 1. El translocador de nucleótidos de adenín (ANT), ubicado en la membrana interna; 2. La ciclofilina
D, ubicada en la matriz y 3. El VDAC o porina, localizado en la membrana externa. Adicionalmente, se han encontrado receptores de benzodiacepinas unidos al poro en la membrana externa, creatín quinasas en el espacio intermembranal y hexoquinasas II ligadas al VDAC en la fase citosólica de la membrana externa, así como proteínas Bax/Bcl-2, Figura 3 (32).

El VDAC es normalmente permeable a solutos de 1.5 $\mathrm{kDa}$, lo que permite el libre intercambio de sustratos de la cadena respiratoria tales como el NADH y el FADH, el ATP/ADP entre el espacio intermebranal y el citosol. En contraste, la membrana interna es casi impermeable lo que permite generar el gradiente electroquímico 
de protones usado en la fosforilación oxidativa. Sin embargo, la permeabilidad de ambas membranas puede ser interrumpida, como se ha demostrado in vitro (32). De esta forma, la apertura del canal en la membrana interna disipa el gradiente de $\mathrm{H}^{+}$a través de la membrana, desacoplando la cadena respiratoria de la producción de ATP. Como resultado se hincha la matriz, lo que provoca la ruptura de la membrana externa permitiendo la salida de las moléculas proapoptóticas, Figura 3 (33).

Aunque se ha escrito mucho sobre el papel regulador que podrían tener otras proteínas y sobre los factores que inducen la probabilidad de que el poro se abra, es de resaltar que los inductores fisiológicos son importantes en su función. Se conoce que el poro se cierra cuando existe una baja carga energética, probablemente para optimizar la fosforilación oxidativa, mientras que en presencia de una alta carga energética se abre, posiblemente con el fin de liberar, en forma de calor, la energía producida por la cadena respiratoria. Es así como la entrada de calcio al citoplasma puede cerrar el poro, lo que obliga a la mitocondria a producir el ATP que necesita la célula para su funcionamiento. Si se comprende la permeabilidad del poro, es posible que se pueda llegar a controlar la muerte celular accidental en procesos como la isquemia, enfermedades neurodegenerativas, entre otras.

\section{La familia Bcl-2 y su interacción con el mPTP}

La familia de proteínas Bcl-2 (homólogo del protooncogen responsable del linfoma folicular humano) es determinante en el control de la vida y la muerte de la célula. Estas proteínas se sintetizan justamente en la membrana de la mitocondria y juegan un rol pro o antiapoptótico, ya que pueden aumentar la permeabilidad de la membrana o disminuirla hasta bloquear el escape de citocromo c y de AIF (34). Las proteínas sintetizadas en esta familia son: Bcl-2, Bcl-xL, Bcl W y BRAG, que inhiben la apoptosis. Mediante fosforilación se originan proteínas con acción proapoptótica como Bax, Bak, Bad, y Bcl x 5, pues producen una caída del potencial transmembranal con el consecuente aumento en la permeabilidad membranal. Además, actúan como activadores de las vías proapoptóticas Fas y TNF y de algunas caspasas (35).

Un segundo mecanismo, a través del cual el citocromo $c$ puede ser liberado al citosol, es a través de un canal que se forma en la membrana externa mitocondrial, cuando proteínas de la familia de $\mathrm{Bcl}-2$ como Bax y Bak, que se encuentra normalmente en el citosol, se translocan a la mitocondria y se oligomerizan para formar una estructura de poro durante la apoptosis. Estas proteínas forman un canal que permite la salida de citocromo c (36). Además del efecto directo que se cree tienen las proteínas de la familia Bcl-2 sobre la permeabilidad mitocondrial, también se ha reportado que Bax podría tener una función independiente estimulando la salida de calcio del retículo endoplásmico y dirigiéndolo hacia la mitocondria. El mecanismo que favorece este movimiento no se ha determinado, pero se ha sugerido que podría involucrar los sitios de contacto entre estos dos organelos (37). Otros autores proponen que el calcio mitocondrial puede promover la incorporación de Bax a la membrana externa (38-40), aunque también se ha reportado la liberación de citocromo $c$ inducida por Bax independiente de calcio (41).

La subfamilia $\mathrm{BH} 3$ parece ser guardiana del daño celular y crítica para desencadenar la apoptosis. Son proteínas inductoras de muerte que subyacen a varios mecanismos de control $(42,43)$. Algunas proteínas se regulan a nivel transcripcional, como es el caso de noxa hrk(44), cuya expresión se induce en respuesta a estímulos proapoptóticos. Otras lo hacen a través de modificaciones postransduccionales como Bid (45), que se mantiene inactivo hasta que es cortadas por una caspasa, lo que genera el fragmento tBid, o Bim, que es secuestrado por los microtúbulos al interactúar con la dineina LC8 (46). Bad es un ejemplo de la regulación de la actividad por fosforilación $(47,48)$, cuando está desfosforilada se asocia a $\mathrm{Bcl}-\mathrm{X}_{\mathrm{L}}$ en la mitocondria y promueve la muerte, en cambio, al ser fosforilada se encuentra en el citoplasma asociada a la proteína chaperona 14-3-3, que se unen a proteínas fosforiladas en serinas y pierde la capacidad de interactuar con Bcl-X $\mathrm{L}_{\mathrm{L}}$ La cinasa Akt es la responsable de la activación e inactivación de $\operatorname{Bad}(49,50)$.

\section{Proyecciones}

Es ahora claro que la mitocondria juega un papel crítico en la muerte celular en la regulación tanto de la apoptosis como de la necrosis. La permeabilización de la membrana mitocondrial y liberación de proteínas al espacio intermembranal son características importantes de estos dos mecanismos. La apoptosis es un proceso complejo 
que merece ser estudiado no sólo por su relevancia en el funcionamiento normal de los organismos, sino porque su desregulación favorece el surgimiento de enfermedades como el cáncer o las que involucran degeneración celular como en las enfermedades neurogenerativas. Entender los mecanismos moleculares implicados en la regulación de la muerte celular y su relación con las vías de señalización, incrementa el conocimiento y comprensión sobre la formación y funcionamiento de los organismos y permite el diseño y la creación de nuevos potenciales terapéuticos.

\section{Agradecimientos}

Financiado por la DIB - Universidad Nacional de Colombia, código No. 8009100 y Colciencias código No. 110145221189.

\section{Referencias}

1. Hengartner MO. The biochemistry of apoptosis. Nature. 2000;12;407:770-776.

2. Amarante-Mendes GP, Green DR.The regulation of apoptotic cell death. Braz J Med Biol Res. 1999;32:1053-1061.

3. Alberts B,.Johnson A, Lewis J, RaffM, Roberts K, Walter P. Molecular biology of the cell. Omega Eds, España. 2002. pg. 767-769.

4. Lodish H. Biología celular y molecular. Médica Panamericana Eds., Madrid, 2006.pg. 513-634

5. Lehninger D, Michael N, Cox M. Principles of Biochemistry. Fourth Edition.2002.pg. 659-670

6. Geydan, Gil, Giraldo, González, Jaramillo, Maes tre, McEwen, Muñetón, Ossa, Parra, Patiño, Ramírez, Rodríguez, Rojas Rugeles, Segura, Spinel, Yildiz, Vásquez. Biología de la célula. 1ª Ed. Colombia: Fondo Editorial Biogénesis. Mayo de 2006.

7. Grimm S, Brdiczka D. The permeability transition pore in cell death. Apoptosis. 2007;12:841-855.

8. Leist $M$, Jäättelä M. Four deaths and a funeral: from caspases to alternative mechanisms. Nat Rev Mol Cell Biol. 2001;2:589-598.

9. De Souza-Pinto NC, Wilson DM 3rd, Stevnsner TV, Bohr VA Mitochondrial DNA, base excision repair and neurodegeneration. DNA Repair (Amst). 2008;1:1098-1109.

10. Arboleda G, Huang TJ, Waters C, Verkhratsky A, Fernyhough P, Gibson RM. Insulin-like growth factor-1-dependent maintenance of neuronal metabolism through the phosphatidylinositol 3-kinaseAkt pathway is inhibited by C2-ceramide in CAD cells. Eur J Neurosci. 2007;25:3030-3038.

11. Vander Heiden MG, Li XX, Gottleib E, Hill RB, Thompson CB, Colombini M. Bcl-xL promotes the open configuration of the voltagedependent anion channel and metabolite passage through the outer mitochondrial membrane.J Biol Chem. 2001;276:19414-19419.

12. Park JM, Greten FR, Wong A, Westrick RJ, Arthur JS, Otsu K, Hoffmann A, Montminy M, Karin M. Signaling pathways and genes that inhibit pathogen-induced macrophage apoptosis--CREB and NF-kappaB as key regulators. Immunity. 2005;23:319-329.
13. Zou H, Henzel WJ, Liu X, Lutschg A, Wang X. Apaf-1, a human protein homologous to C. elegans CED-4, participates in cytochrome c-dependent activation of caspase-3. Cell. 1997;90:405-413.

14. Adams JM, Cory S. Life-or-death decisions by the Bcl-2 protein family. Trends Biochem Sci. 2001;26:61-66.

15. Suen DF, Norris KL, Youle RJ. Mitochondrial dynamics and apoptosis. Genes Dev. 2008;22:1577-1590.

16. Susin SA, Lorenzo HK, Zamzami N, Marzo I, Snow BE, Brothers GM, et al. Molecular characterization of mitochondrial apoptosisinducing factor. Nature. 1999;397:441-446.

17. Green D, Kroemer G. The central executioners of apoptosis: caspases or mitochondria? Trends Cell Biol. 1998;8:267-271.

18. Li LY, Luo X, Wang X. Endonuclease G is an apoptotic DNase when released from mitochondria. Nature. 2001;412:95-99.

19. Zamzami N, Susin SA, Marchetti P, Hirsch T, Gómez-Monterrey I, Castedo M, Kroemer G. Mitochondrial control of nuclear apoptosis. J Exp Med. 1996;183:1533-1544.

20. Susin SA, Daugas E, Ravagnan L, Samejima K, Zamzami N, Loeffler $\mathrm{M}$, et al. Two distinct pathways leading to nuclear apoptosis. J Exp Med. 2000;192:571-580.

21. Hengartner MO. The biochemistry of apoptosis. Nature. 2000;407:770-776

22. Thorburn A. Death receptor-induced cell killing. Cell Signal. 2004;16:139-144.

23. Liu X, Kim CN, Yang J, Jemmerson R, Wang X. Induction of apoptotic program in cell-free extracts: requirement for dATP and cytochrome c. Cell. 1996;86:147-157.

24. Verhagen AM, Ekert PG, Pakusch M, Silke J, Connolly LM, Reid GE, Moritz RL, Simpson RJ, Vaux DL Identification of DIABLO, a mammalian protein that promotes apoptosis by binding to and antagonizing IAP proteins. Cell. 2000;102:43-53.

25. Du C, Fang M, Li Y, Li L, Wang X. Smac, a mitochondrial protein that promotes cytochrome c-dependent caspase activation by eliminating IAP inhibition. Cell. 2000;102:33-42.

26. Parone PA, James D, Martinou JC. Mitochondria: regulating the inevitable. Biochimie. 2002;84:105-111.

27. Orrenius S, Gogvadze V, Zhivotovsky B. Mitochondrial oxidative stress:implications for cell death. Annu Rev Pharmacol Toxicol. 2007; 47:143-83.

28. Veenman L, Shandalov Y, Gavish M. VDAC activation by the 18 $\mathrm{kDa}$ translocator protein (TSPO), implications for apoptosis. J Bioenerg Biomembr. 2008;40:199-205.

29. Susin SA, Lorenzo HK, Zamzami N, Marzo I, Brenner C, Larochette N, et al. Mitochondrial release of caspase-2 and -9 during the apoptotic process. J Exp Med. 1999;189:381-394.

30. Tinel A, Tschopp J. The PIDDosome, a protein complex implicated in activation of caspase- 2 in response to genotoxic stress. Science. 2004; 304:843-846

31. Gogvadze V, Orrenius S. Mitochondrial regulation of apoptotic cell death. Chem Biol Interact. 2006;163:4-14.

32. Zamzami N, Kroemer G. The mitochondrion in apoptosis: how Pandora's Box opens. Nat Rev Mol Cell Biol. 2001;2:67-71.

33. Shoshan-Barmatz V, Keinan N, Zaid H. Uncovering the role of VDAC in the regulation of cell life and death.J Bioenerg Biomembr. 2008;40:183-191. 
34. Shimizu S, Narita M, Tsujimoto Y. Bcl-2 family proteins regulate the release of apoptogenic cytochrome $\mathrm{c}$ by the mitochondrial channel VDAC. Nature. 1999;399:483-487.

35. Shimizu S, Eguchi Y, Kamiike W, Funahashi Y, Mignon A, Lacronique V, Matsuda H, Tsujimoto Y. Bcl-2 prevents apoptotic mitochondrial dysfunction by regulating proton flux. Proc Natl Acad Sci USA. 1998;95:1455-1459.

36. ZhaJ, Harada H, YangE, JockelJ, Korsmeyer SJ. Serine phosphorylation of death agonist $\mathrm{BAD}$ in response to survival factor results in binding to 14-3-3 not BCL-X(L) Cell. 199615;87:619-628.

37. Luo X, Budihardjo I, Zou H, Slaughter C, Wang X. Bid, a $\mathrm{Bcl} 2$ interacting protein, mediates cytochrome $\mathrm{c}$ release from mitochondria in response to activation of cell surface death receptors. Cell. 1998;94:481-490.

38. Murphy KM, Streips UN, Lock RB. Bcl-2 inhibits a Fas-induced conformational change in the Bax $\mathrm{N}$ terminus and Bax mitochon drial translocation.J Biol Chem. 2000;275:17225-17228.

39. Narita M, Shimizu S, Ito T, Chittenden T, Lutz RJ, Matsuda $H$, Tsujimoto Y. Bax interacts with the permeability transition pore to induce permeability transition and cytochrome $\mathrm{c}$ release in isolated mitochondria. Proc Natl Acad Sci USA. 19988;95:14681-14686.

40. Marzo I, Brenner C, Zamzami N, Jürgensmeier JM, Susin SA, Vieira HL, Prévost MC, Xie Z, Matsuyama S, Reed JC, Kroemer G. Bax and adenine nucleotide translocator cooperate in the mitochondrial control of apoptosis. Science. 1998;281:2027-2031.

41. Rizzuto R, Brini M, Murgia M, Pozzan T. Microdomains with high $\mathrm{Ca} 2+$ close to IP3-sensitive channels that are sensed by neighboring mitochondria. Science. 1993;262:744-747.
42. Huang DC, Strasser A. BH3-Only proteins-essential initiators of apoptotic cell death. Cell. 2000;103:839-842.

43. Kelekar A, Thompson CB. Bcl-2-family proteins: the role of the BH3 domain in apoptosis. Trends Cell Biol. 1998;8:324-330.

44. Zhivotovsky B, Kroemer G. Apoptosis and genomic instability. Nat Rev Mol Cell Biol. 2004;5:752-762.

45. Desagher S, Osen-Sand A, Nichols A, Eskes R, Montessuit S, Lauper $\mathrm{S}$, et al. Bid-induced conformational change of $\mathrm{Bax}$ is responsible for mitochondrial cytochrome $\mathrm{c}$ release during apoptosis. J Cell Biol. 1999; 144:891-901.

46. Puthalakath H, Huang DC, O’Reilly LA, King SM, Strasser A. The proapoptotic activity of the Bcl-2 family member Bim is regulated by interaction with the dynein motor complex. Mol Cell. 1999;3:287-296.

47. Ayllón V, Fleischer A, Cayla X, García A, Rebollo A. Segregation of Bad from lipid ra冈s is implicated in the induction of apoptosis. J Immunol. 2002; 168:3387-3393.

48. Fleischer A, Ghadiri A, Dessauge F, Duhamel M, Cayla X, Garcia A, Rebollo A. Bad-dependent ra $\bigotimes_{s}$ alteration is a consequence of an early intracellular signal triggered by interleukin- 4 deprivation. Mol Cancer Res. 2004;2:674-684.

49. del Peso L, González-García M, Page C, Herrera R, Nuñez G. Interleukin-3-induced phosphorylation of $\mathrm{BAD}$ through the protein kinase Akt. Science. 1997;278:687-689.

50. Shimamura H, Terada Y, Okado T, Tanaka H, Inoshita S, Sasaki S. The PI3-kinase-Akt pathway promotes mesangial cell survival and inhibits apoptosis in vitro via NF-kappa B and Bad. J Am Soc Nephrol. 2003; 14:1427-1434. 